\title{
Poem
}

I attended a presentation at the Massachusetts Alzheimer's conference in May 2003. This stellar presentation by three dedicated scientists pursuing treatments and understanding of this disease with the end goal of eradicating the pain and suffering it causes. These scientists were focused on solving a problem, but also seeing and communicating how their science could help others and their hopes for the future. I was intrigued by the science, interested in the different directions that were being taken, but most of all, I was hoping that the journey to effective treatment would be mercifully short, and yet knowing it is not. For you see, my own mother has been diagnosed not with this disease of the mind, but another that leaves her mind intact while her body disintegrates; ALS, or Lou Gerhig's disease. I hope and pray for all families living with Alzheimer's or ALS and the scientists who are working for treatment and cures.

May 2003

Elaine M. Seidel

\section{IT Department}

University of Massachusetts Lowell

Lowell, MA 01854, USA

E-mail: Elaine_seidel@uml.edu

\section{On We Fight}

On we fight

In guerilla fashion

Small battles

Small victories

More failures

That push us in new directions

To try, to strive yet again

Our target not

Global preservation

But a reduction of percentages

Watching close to achieve

A change in the mitochondria...

A shift at the genetic level

Yet

We stumble as humans

The most scientific of us all

See the immaturity of

Our species

The weakness of our tools

of understanding

But then, a marker found

Not expected

Taking us on new paths

Of enlightenment 